Annales Geophysicae (2002) 20: 107-113 (c) European Geophysical Society 2002

\title{
A study of the relationship between cloud-to-ground lightning and precipitation in the convective weather system in China
}

\author{
Y. Zhou ${ }^{1}$, X. Qie ${ }^{1}$, and S. Soula ${ }^{2}$ \\ ${ }^{1}$ Cold and Arid Regions Environmental and Engineering Research Institute, Chinese Academy of Science, Lanzhou, China \\ ${ }^{2}$ Laboratoire d'Aerologie, UMR 5560 UPS/CNRS, OMP, 14 av. E. Belin 31400 Toulouse, France
}

Received: 25 August 2000 - Revised: 16 July 2001 - Accepted: 18 July 2001

\begin{abstract}
In this paper, the correlation between cloud-toground (CG) lightning and precipitation has been studied by making use of the data from weather radar, meteorological soundings, and a lightning location system that includes three direction finders about $40 \mathrm{~km}$ apart from each other in the Pingliang area of east Gansu province in P. R. China. We have studied the convective systems that developed during two cold front processes passing over the observation area, and found that the CG lightning can be an important factor in the precipitation estimation. The regression equation between the average precipitation intensity $(R)$ and the number of CG lightning flashes $(L)$ in the main precipitation period is $R=1.69 \ln (L)-0.27$, and the correlation coefficient $r$ is 0.86 . The CG lightning flash rate can be used as an indicator of the formation and development of the convective weather system. Another more exhaustive precipitation estimation method has been developed by analyzing the temporal and spatial distributions of the precipitation relative to the location of the CG lightning flashes. Precipitation calculated from the CG lightning flashes is very useful, especially in regions with inadequate radar cover.
\end{abstract}

Key words. Meteorology and atmospheric dynamics (atmospheric electricity; lightning; precipitation)

\section{Introduction}

The observation of precipitation in convective weather systems by utilizing lightning location systems and multi-parameter radar or routine weather radar has been extensively explored worldwide for more than ten years (Holle, et al., 1997; Qie et al., 1993). Many significant results have been obtained from the correlations between the CG lightning activities and the radar reflectivity, and between the CG lightning activities and the precipitation (Sheridan et al., 1997, Petersen and Rutledge, 1998; Soula et al., 1998). The results indicate a strong relationship between the CG

Correspondence to: X. Qie (qiex@ns.lzb.ac.cn) lightning flash frequency and the precipitation intensity. Piepgrass et al. (1982) found that the CG lightning flash peak frequency appeared a few minutes earlier than the peak precipitation intensity on the ground in a thunder cell. By analyzing the radar reflectivity and the CG lightning location data, Qie et al. (1993) also found that the peak value of the CG lightning flash frequency during the development of a thunder cell could be 10-30 minutes in advance of forecasting the appearance of hailstones. The CG lightning flashes usually occur in the strong radar reflectivity region, i.e. in the high precipitation intensity area (Tapia et al., 1998) or just in the outside edge of the high precipitation intensity area (Dye et al., 1986; Ge et al., 1995). Therefore, the CG lightning flash activities of a thunderstorm could be used in local short-term forecasting of heavy rain or in precipitation estimation (Williams et al., 1989; Petersen and Rutledge, 1998; Soula et al., 1998). In addition, the data of CG lightning can be used to forecast flash flood or hailstone weather (Soula et al., 1998; Zhou et al., 1999). Further high precipitation corresponds to strong atmospheric electrical activity in convective weather systems, but not in stratiform cloud precipitation weather. Until now, however, most of the former studies have been qualitative analyses. In this paper, we will analyze the relationship between the CG lightning and CAPE (convective available potential energy) radar reflectivity, as well as the precipitation in the convective weather system, and provide a quantitative relationship between the precipitation and CG lightning flash frequency.

\section{Experiment conditions}

The synthesis observation of convective weather processes was carried out in Pingliang (E $106^{\circ} 41^{\prime}$, N $35^{\circ} 34^{\prime}$ ) of Gansu province in P. R. China from June to August of 1997. Routine meteorological radar (wave length $3 \mathrm{~cm}$ ), dual linear polarization radar, and three Direction Finders (DFs) were used in this observation. The three DFs were setup in Liupan Mountain, Penyang, and Pingliang, as illustrated in Fig. 1. 


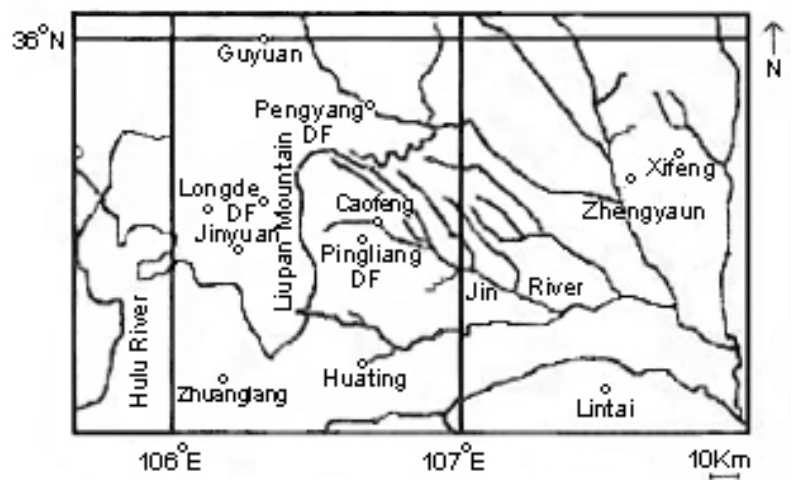

Fig. 1. The distribution of the main precipitation observation stations in the eastern Gansu area.

They were located in an isosceles triangle around the Liupan Mountain, which is the most favorable zone for convection triggering. The distances between the two sites were $40 \mathrm{~km}, 40 \mathrm{~km}$, and $30 \mathrm{~km}$, respectively. This CG lightning flash detection system is based on the LLP technique (Krider et al., 1976). Each station was equipped with a crossed loop antenna that detects the magnetic field radiated by each return stroke of the CG flashes. Thus, they provided the direction from the station to the ground-strike point. The detection range of a station was about $200 \mathrm{~km}$ and, therefore, all the area of Fig. 1 was covered by the detection system with the same efficiency. This efficiency of detection was about $90 \%$, and the accuracy was better than about $1 \mathrm{~km}$ for $95 \%$ of these detection. The analyzed data was chosen from the convective system between 25 July and 31 July 1997. During this period, two cold front processes crossed over the observation area and produced a series of thundercells. The climatic analysis of the CG lightning and precipitation shows that there is a good correlation between the precipitation and the CG lightning flash frequency in convective weather systems. The main precipitation observation stations in the Pingliang area of the eastern part of the Gansu province are also shown in Fig. 1. About $70 \%$ of the total annual precipitation occurs during the summer season (from June through August) in the Pingliang area. The convective weather system in this area usually occurs from 13:30 to 19:30 (Beijing time), and the peak values of precipitation and the CG lightning flash frequency occur almost simultaneously during the mature stage of a convective weather process (15:30-18:00). During the dissipation stage (usually after 18:00), the peak values of precipitation and the CG lightning flash frequency do not occur simultaneously.

The CG lightning observations provide useful climatological information on the spatial distribution of convective precipitation. Figure 2 shows the spatial distribution of lightning frequency in units of CG flashes per square kilometer from June to August 1997. The point $(0,0)$ is located at Pingliang. It can be seen that the maximum appears in the south of Pingliang. The appearance of the maximum is closely linked

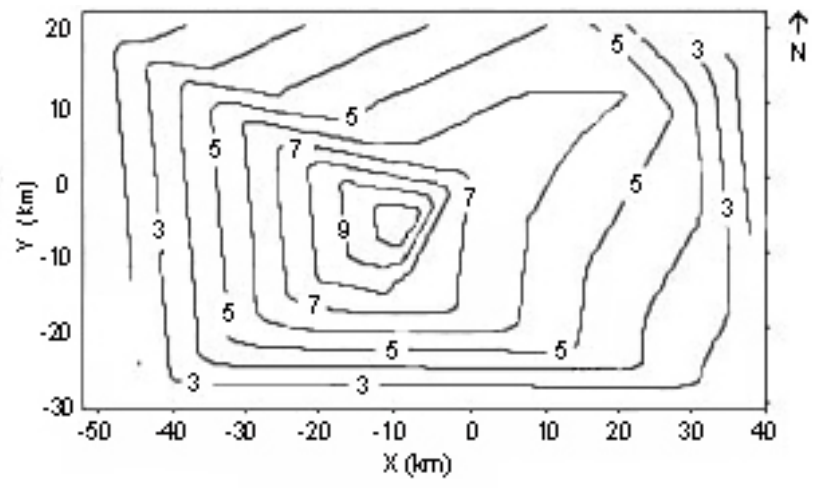

Fig. 2. The spatial distribution of lightning frequency in units of CG flashes per square kilometer from June to August in 1997 in the observation area.

with the landform of the area of the eastern part of the Gansu province. The rising elevation of the Liupan Mountain facilitates the formation of strong convective weather systems, so relatively concentrated CG lightning flashes appear in the area. Figure 3 shows the variation in the percentage of total CG lightning (solid line) and the precipitation (dashed line) for all studied convective weather days in the Pingliang area. The general variation in the precipitation is quite similar to that of the CG lightning. In every studied convective weather day, the maximum values of the precipitation and the CG lightning appear approximately at 16:00.

\section{The thunderstorm intensity analysis}

The thunderstorm intensity assessment was performed by investigating the data from the DFs and the dual linear polarization radar during the observation period in 1997. The thunderstorm identification tracking and a very short-time storm-forecasting algorithm was used to compute the thunderstorm parameters. The thunderstorm parameters include precipitation area, location of the reflectivity centroid, thunderstorm top height, thunderstorm volume, precipitation intensity, and spatial average precipitation. The equation for the precipitation estimated by the dual linear polarization radar is

$R=A Z_{H} Z_{D R}^{B}$

(Hongfa and Baoxiang, 1996). In this equation, $R$ is the precipitation intensity, $A$ and $B$ are constants (they are varied with the different raindrop spectrums), $Z_{H}$ is the radar reflectivity, and $Z_{D R}$ is the radar differential reflectivity.

Figure 4 gives the relationship between radar reflectivity and CG lightning flashes occurring between 18:00 and 18:05 (Beijing Time) on 27 July 1997. In the figure, the $x$-axis and $y$-axis represent the ranges from west to east and from north to south, respectively, in the observation area. $(0,0)$ is located at Pingliang. The solid lines in the figure are the isolines of radar reflectivity. The triangles in the figure are the 


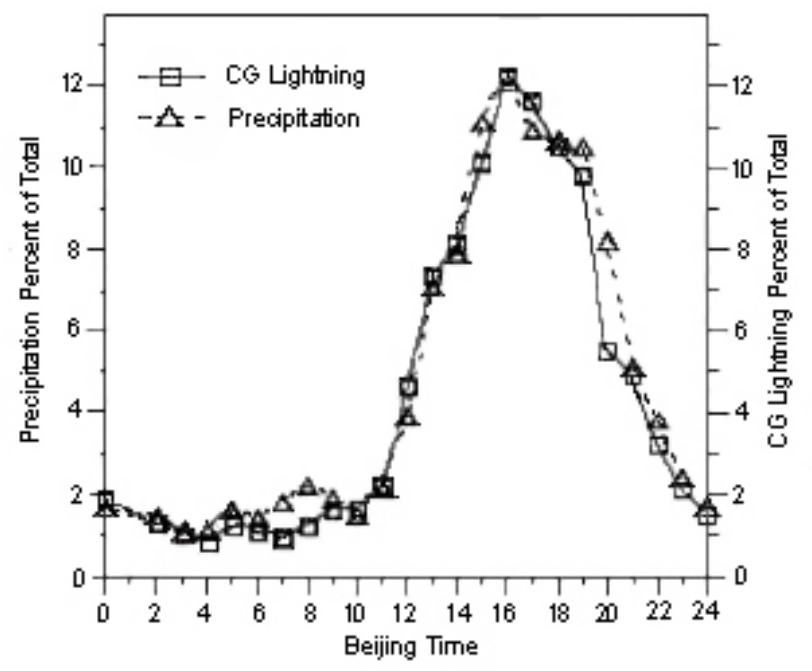

Fig. 3. The variation in the percentage of the total CG lightning and precipitation for all events studied.

CG lightning flashes. In a time series, a good correlation exists between radar reflectivity and the CG lightning flashes, and also between the precipitation intensity and the CG lightning flash frequency. Such a correlation exists in both the mature and the dissipating stages. It can be seen from the radar echoes that the thunderstorms with the tallest clouds produced the highest CG lightning flash frequencies and the highest precipitation intensities. In general, the CG lightning flash frequency reaches its maximum value immediately after the cloud top develops to the maximum vertical height, and when the strong reflectivity core reaches the highest altitude in the cloud.

In eastern Gansu, for all the thunderstorms, the occurrence of the CG lightning precedes the development of the cloud centroid in which the reflectivity is greater than $35 \mathrm{dBZ}$. The observations show that the thunderstorm with the maximum total CG lightning number in a given day would produce the highest CG lightning flash frequency. The correlative coefficient between them is 0.96 . No correlation is found between the duration of the thunderstorm and the peak value of the CG lightning flash frequency.

\section{The relationship between CG lightning and precipita- tion}

\subsection{The weather background}

There were two cold front processes that passed through the eastern Gansu province during the period of observation. The first one was between 25 July and $28 \mathrm{July}$, and the second one was between 29 July and 31 July. It was clear to overcast on 25 July without precipitation. The cold front moved close to the observation area on $26 \mathrm{July}$, and an isolated low pressure dominated the area. At the $700 \mathrm{hPa}$ level, the cold air was ad-

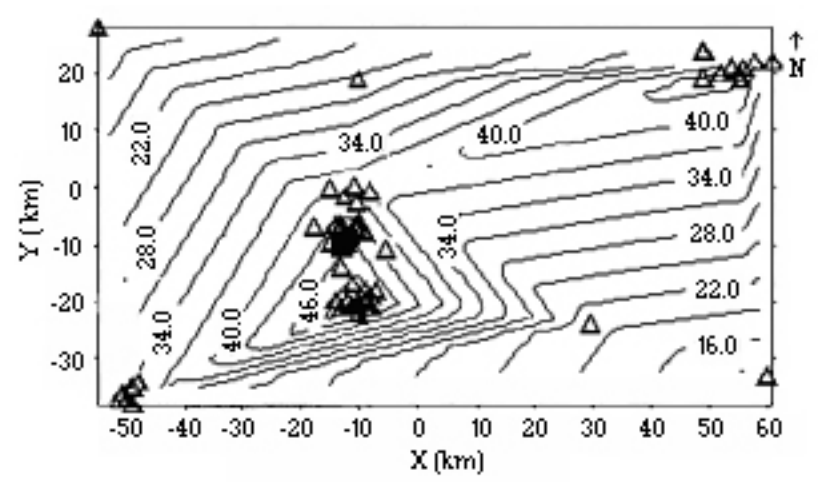

Fig. 4. The relationship between radar reflectivity and CG lightning flashes that occurred between 18:00 and 18:05 (Beijing Time) on 27 July 1997.

vected to the observation area. There was a thunderstorm in part of the area on 26 July. The main rain region was behind the cold front (to the west of the cold front). The precipitation at Longde and Penyang was, respectively, $6.6 \mathrm{~mm}$ and $6.8 \mathrm{~mm}$ from 14:00-20:00. The movement of the cold front was not distinct on 27 July. On this day, there were troughs of low pressure at the levels of $500 \mathrm{hPa}$ and $700 \mathrm{hPa}$ that dominated the observation area. The cold air was also advected to the area. The main precipitation area was in front of the cold front (in the eastern observation area). There were precipitation records in the whole east Gansu area. The precipitation in all 14 stations was above $2.0 \mathrm{~mm}$, with the highest at $49.8 \mathrm{~mm}$ in Huating. On $28 \mathrm{July}$, the cold front had moved out of the area with light to heavy rain, and the warm air was advected to the area at the $700 \mathrm{hPa}$ and $500 \mathrm{hPa}$ levels. The precipitation area was behind the cold front. The highest precipitation was $40.1 \mathrm{~mm}$ at Jingchuan.

The second cold front process moved into the observation area on $29 \mathrm{July}$. At the $700 \mathrm{hPa}$ level, the low pressure was in front of the area. The trough was in the area at the $500 \mathrm{hPa}$ level. It was cloudy without precipitation. The highest precipitation was $24.1 \mathrm{~mm}$ at Penyang on 30 July. The cold front moved out of the area on 31 July. The main precipitation area was behind the cold front. It rained successively all day in the area. The highest precipitation was $18.1 \mathrm{~mm}$ at Zhuanglang.

\subsection{The relationship between CG lightning and CAPE}

Significant CG lightning is readily generated in strong convective weather systems, and can be forecasted from the CAPE. It is interesting to study the relationship between CG lightning and CAPE in order to obtain a more convenient indicator of the convective weather system. In this paper, both weather systems were behind the cold front. Due to the uplifting of the Liupan Mountain, a series of convective weather systems with significant CG lightning was produced. In 7 days (from the 25 to 31 July 1997), two higher values of the daily total number of CG lightning flashes appeared on 27 and 30 July, at 1861 and 3212 flashes, respec- 

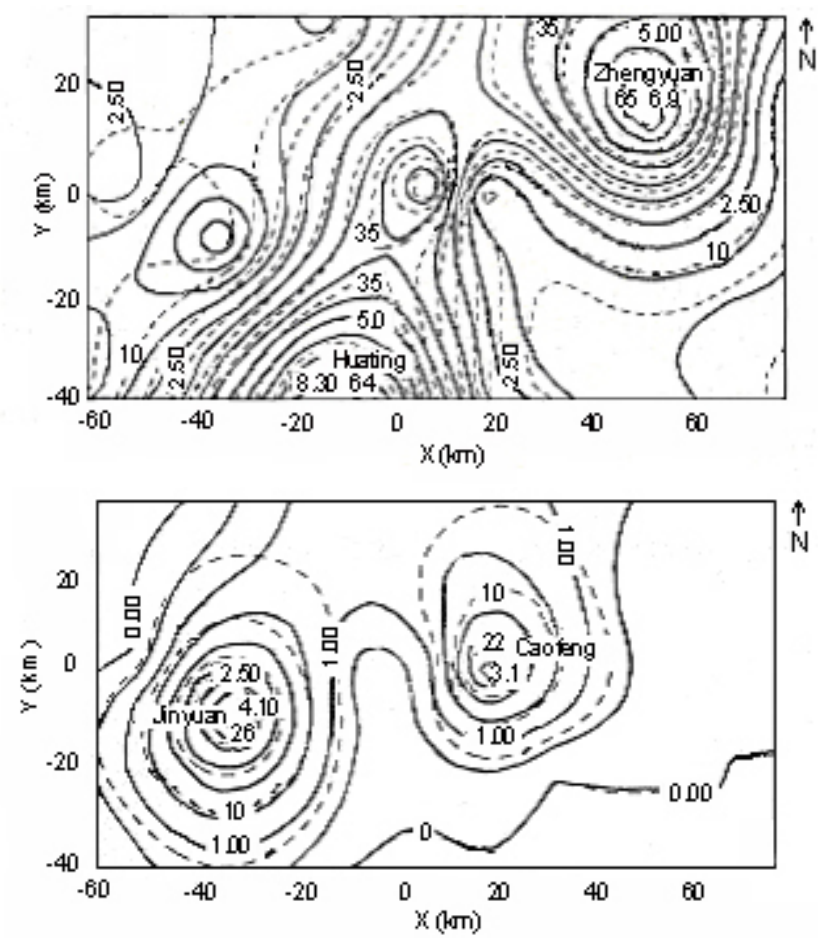

Fig. 5. The isolines of the distribution of the average precipitation intensity (solid line) in the main precipitation period (14:00-20:00) and the isolines of the distribution of the number of CG lightning flashes (dashed line) in the same period: (a) 27 July, (b) 30 July.

tively. Two higher values of CAPE were also calculated on 27 and $30 \mathrm{July}, 3021 \mathrm{~J} / \mathrm{kg}$ and $2878 \mathrm{~J} / \mathrm{kg}$, respectively. Two lower values, $1501 \mathrm{~J} / \mathrm{kg}$ and $1636 \mathrm{~J} / \mathrm{kg}$, were calculated on 26 and 28 July. The evolution of the CG lightning flash activity and that of the CAPE seem to be associated with both of the cold front weather systems. The variation in the total number of CG lightning flashes per day and CAPE at 07:00 (Beijing Time) can also be separated into two different processes: the first from 25 to 28 July, and the second from 29 to 31 July. These two processes corresponded exactly to the two cold front processes. In these two events, the electrification mechanism was strengthened while the strong instability occurred and thus, many CG lightning flashes were produced. However, there is only a tendency and not a tight relationship between the CAPE and the CG lightning flash number for both processes. The CG lightning could be a good indicator of the formation and the development of convective systems. The increase in CAPE is associated with the trigger mechanism of the underlying Earth's surface. With the development of convective weather, the trigger mechanism of the underlying Earth's surface disappears, and the CG lightning is a more convenient method for indicating the development of convective weather systems.
4.3 The relationship between the CG lightning and the average precipitation

When the cold fronts moved into the area, heavy precipitation appeared with numerous strong CG lightning flashes due to the strong instability. In this paper, we studied two cold front processes occurring on 27 July and 30 July in the area, and we analyzed the relationship between the precipitation and the CG lightning. The precipitation in the two days was a mixture of showers and continuous rain. The main precipitation in two days lasted about $180 \mathrm{~min}$. The variation in the CG lightning flash frequency and the precipitation were the same. The CG lightning flash frequency and the precipitation showed maximum values simultaneously over $90 \mathrm{~min}$ during the main precipitation period $(180 \mathrm{~min})$ on $27 \mathrm{July}$; there were 5.2 flashes per $5 \mathrm{~min}$ with $4.2 \mathrm{~mm}$ of rain, respectively. The maximum value of the CG lightning flash frequency appeared over 60 min during the main precipitation period $(180 \mathrm{~min})$ on $30 \mathrm{July}$, while that of the precipitation appeared over 90 min during the same period; there were 2.8 flashes per $5 \mathrm{~min}$ with $1.8 \mathrm{~mm}$ of rain, respectively. The time variation in the radar echo height at $45 \mathrm{dBz}, 35 \mathrm{dBz}$, $25 \mathrm{dBz}, 15 \mathrm{dBz}$ and $1 \mathrm{dBz}$ were almost the same as that of the CG lightning flash frequency in these two days.

We analyzed the data of the CG lightning flashes and the precipitation measured in the same convective weather system in order to study their correlation for estimating the precipitation. Figures $5 \mathrm{a}$ and $5 \mathrm{~b}$ show the isolines of the average precipitation intensity and the CG lightning flashes in the same main precipitation period (14:00-20:00) on 27 July and 30 July. The solid line represents the average precipitation intensity during the main precipitation period, and the dashed line represents the CG lightning flash number in the same time. The Pingliang station is located at $(0,0)$ in the figure. Two strong precipitation intensity centers appeared at $\mathrm{Hu}-$ ating and Zhenyuan on 27 July; they reached $8.3 \mathrm{~mm} / \mathrm{h}$ and $6.9 \mathrm{~mm} / \mathrm{h}$, respectively. The CG lightning flash number also displayed two maximum values in the same period, 64 and 65 , at Huating and Zhenyuan respectively, corresponding to the two maxima in precipitation. There were two strong precipitation intensities at Caofeng and Jinyuan on 30 July; they were $3.1 \mathrm{~mm} / \mathrm{h}$ and $4.1 \mathrm{~mm} / \mathrm{h}$, respectively. The CG lightning flash number also had two maximum values at the same time and same places with the values of 22 and 26, respectively.

By studying the data of precipitation and the CG lightning flashes of 16 stations on 27 July and 30 July, we obtain the regression equation of the average precipitation intensity and the CG lightning flash number in the main precipitation pe$\operatorname{riod}(14: 00-20: 00)$. The equation is as follows :

$R=1.69 \ln (L)-0.27 L \geq 2 r=0.86$,

where $R$ is the average precipitation intensity in the main precipitation period, $L$ is the number of CG lightning flashes in the main precipitation period, and $r$ is the coefficient of correlation. Although the precision of the precipitation estimation by the CG lightning is not as precise as the dual linear polarization radar, the method is simple and easy to perform. 
Table 1. Sounding and CG lightning flash data

\begin{tabular}{cccccc}
\hline Date & $\begin{array}{c}\text { Average wind } \\
\text { direction } \\
\text { between } 3 \\
\text { and } 10 \mathrm{~km} \\
(\text { degree })\end{array}$ & $\begin{array}{c}\text { Average wind } \\
\text { speed } \\
\text { between } 3 \\
\text { and } 10 \mathrm{~km} \\
(\mathrm{~m} / \mathrm{s})\end{array}$ & $\begin{array}{c}\text { CAPE } \\
(\mathrm{J} / \mathrm{kg})\end{array}$ & $\begin{array}{c}\text { Average } \\
\mathrm{RPF} \\
\left(10^{6} \mathrm{~kg} / \mathrm{CG}\right. \\
\text { flash })\end{array}$ & $\begin{array}{c}\text { Total CG } \\
\text { lightning } \\
\text { flash number } \\
\text { during } \\
\text { thunderstorm }\end{array}$ \\
\hline $25 / 7 / 1997$ & 155 & 2.9 & 1965 & 16 & 1068 \\
$26 / 7 / 1997$ & 236 & 4.9 & 1501 & 21 & 921 \\
$27 / 7 / 1997$ & 330 & 5.5 & 3021 & 28 & 1861 \\
$28 / 7 / 1997$ & 95 & 0.8 & 1636 & 19 & 934 \\
$29 / 7 / 1997$ & 286 & 3.2 & 2640 & 33 & 2002 \\
$30 / 7 / 1997$ & 109 & 2.8 & 2878 & 35 & 3212 \\
$31 / 7 / 1997$ & 296 & 1.7 & 1864 & 14 & 1876 \\
\hline
\end{tabular}

\section{Precipitation estimation from the CG lightning activ- ity}

There are several methods for precipitation estimation, such as using the relationship of $Z-R$ for routine weather radar, using the relationships of $Z_{H}$ and $Z_{D R}-R$ for dual linear polarization radar, or using the meteorology satellite (for example: TRMM and GMS) to measure the precipitation by remote sensing. Due to specific problems for each one of the previous methods, it is useful for meteorological scientists to utilize other methods of precipitation estimation. We consider some details of precipitation estimation from the $\mathrm{CG}$ lightning in the remainder of this section.

\subsection{Precipitation-CG lightning ratio analyses}

For each storm, the total convective precipitation is divided by the total number of CG lightning flashes to obtain an estimated PPF (Precipitation Per CG Flash), which is the precipitation per CG flash. PPF values in this study ranged from 14 to $35 \times 10^{6} \mathrm{~kg}$ per CG flash. The median PPF was $24 \times 10^{6} \mathrm{~kg}$ per CG flash.

Table 1 gives information on the atmospheric conditions for the days on which the storms occurred. The sounding was taken at 07:00 (Beijing time). For the study of PPF variability with convective regime, the criteria used by Lopez et al. (1991) are adopted. In their study, the convective regimes of central Florida are classified according to the direction of the prevailing synoptic wind.

Almost all convective systems in the eastern area of the Gansu province occur when northwest winds prevail. The variability of the PPF and of the relationship between the peak CG lightning flash frequency and the convective precipitation can be significantly reduced when considering only the days with the same convective type. This shows that the amount of precipitation required for a discharge occurrence remains relatively constant under similar conditions. The PPF for a given convective regime can be experimentally estimated through a statistical analysis of a set of thunderstorms taking place under this particular regime. The variability within a given convective regime can be partly explained in terms of the variability of the thunderstorm intensity. Strong thunderstorms with high CAPE values and CG lightning flash numbers tend to produce higher PPF values than moderate thunderstorms. The PPF also changes within the lifetime of a thunderstorm. For all of the analyzed thunderstorms, the PPF reached the minimum when the CG lightning flash frequency peaked. Following this peak, the $\mathrm{CG}$ lightning flash frequency decreased more rapidly than the precipitation. The higher PPF was produced as the thunderstorms decayed.

Many studies have shown an inverse correlation between PPF and CAPE. Buechler et al. (1990) found that decreases in PPF are due to the strengthening of the updraft in higher CAPE observation days. Here, the maximum updraft speed is proportional to the square root of CAPE (Weisman, 1986). The reason for the decrease in PPF may be that the strong updrafts strengthen the non-induction electrification mechanism, and thus, the CG lightning is produced quickly. On the other hand, the precipitation may be affected by the strong updraft and may not reach the ground easily.

\subsection{Precipitation estimated by CG lightning with using PPF}

The estimation of convective precipitation for a given thunderstorm from the CG lightning flash observation is based on the use of the following equation that expresses the spatial and temporal distribution of precipitation intensity (Tapia et al., 1998):

$I(x, y, t)=C \sum_{i=1}^{N} Z f\left(t, T_{i}\right) g\left(x, y, D_{i}\right)$,

where $I(x, y, t)$ is the precipitation intensity at time $t$ and location $(x, y)$, and its units are $(\mathrm{mm} / \mathrm{h}) . N$ is the total number of CG lightning flashes, $T_{i}$ is the time of the $i^{\text {th }}$ CG lightning flash, and $D_{i}$ is the distance of the $i^{\text {th }} \mathrm{CG}$ lightning flash from 

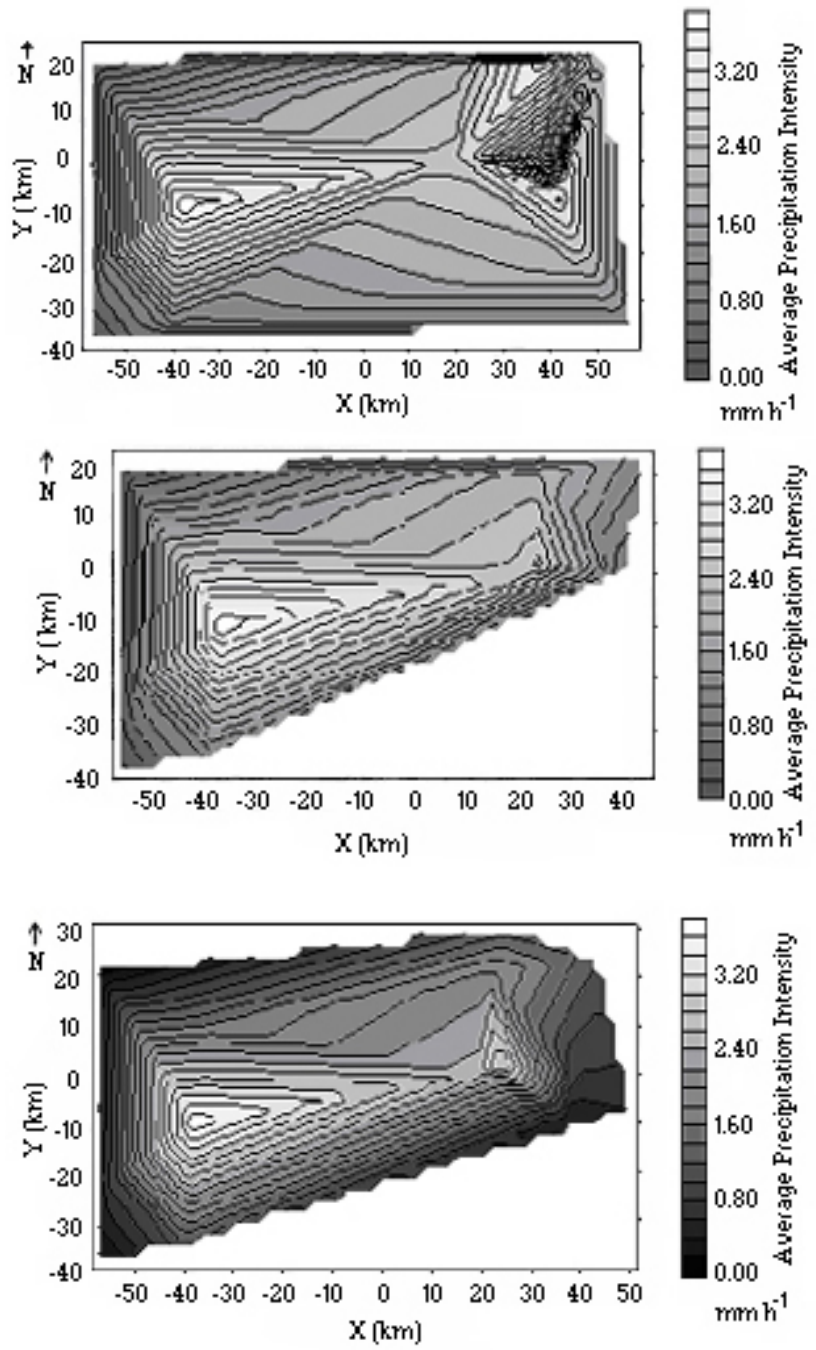

Fig. 6. The main precipitation period: (a) average precipitation intensity of radar estimated, (b) average precipitation intensity of CG lightning estimated, (c) the real average precipitation intensity measured by rain gauges; unit is $\mathrm{mm} / \mathrm{h}$

the position $(x, y) \cdot g\left(x, y, D_{i}\right)$ is a term at location $(x, y)$, a distance Di from the $i^{\text {th }}$ CG lightning flash given by:

$g\left(x, y, D_{i}\right)= \begin{cases}1, & D_{i}<5 \mathrm{~km} \\ 0, & D_{i} \geq 5 \mathrm{~km} .\end{cases}$

In the calculation, the precipitation is uniformly distributed within a $10 \mathrm{~km}$ diameter circle around the location of the CG lightning, corresponding to the condition given by Tapia et al. (1998). As a matter of fact, most CG lightning flashes occur within the area of heavier precipitation. Carte and Kidder (1997) have observed that the area of highest CG lightning density occurs in the vicinity of the heaviest precipitation, but it does not coincide with the reflectivity core of the thunderstorm. Watson et al. (1994) found that the CG lightning tends to avoid the region of highest reflectivity, and is more likely to occur just outside of it. In other words, the lightning core is not always colocated with the reflectivity core. Therefore, it is difficult to apply a distribution function of the precipitation around the location of a given lightning flash.

The temporal distribution is determined by $f\left(t T_{i}\right)$ as a function of time $t$ from a CG lightning flash at time $T_{i}$, accounting to:

$f\left(t, T_{i}\right)= \begin{cases}1, & \left|t-T_{i}\right|<\Delta t / 2 \\ 0, & \left|t-T_{i}\right| \geq \Delta t / 2,\end{cases}$

where $\Delta t=5$ minutes. This time interval is also considered for the cumulative precipitation estimation. In other words, the precipitation intensity is considered constant during the time interval $\Delta t$.

Equation (2) can be used to estimate convective precipitation from the CG lightning flash observation. It is necessary to know the term $Z$, which is the PPF for the thunderstorm in units of kilograms per CG lightning flash. The median PPF observed in thunderstorms in the eastern area of the Gansu province is $24 \times 10^{6} \mathrm{~kg}$ per CG flash. $C$ is a unit conversion factor $\left(C=0.153 \times 10^{-6} \mathrm{~kg}^{-1} \mathrm{~mm} \mathrm{~h}^{-1}\right)$. A single CG lightning flash produces, therefore, a cumulative precipitation of $0.31 \mathrm{~mm}$. The effective area of $25 \pi \mathrm{km}^{2}$ is chosen to reflect the characteristic size of the thunderstorms in the eastern area of Gansu province.

\subsection{Application to 30 July}

We take 30 July 1997 as an example to verify the arithmetic. Figures $6 a, 6 b$, and $6 c$ express the average precipitation intensities in the main precipitation period obtained from the radar data, the CG lightning data, and the rain gauge, respectively. The highest average precipitation intensity appears to the west of the detection area. It is close to Pingliang, and is $3.8 \mathrm{~mm} / \mathrm{h}$. The characteristic is coherent in Figs. $6 \mathrm{a}, 6 \mathrm{~b}$, and $6 \mathrm{c}$. This shows that the capability of the estimation of precipitation by the radar data and the CG lightning are coherent near Pingliang, but different northeast of the area that is far away from Pingliang. The average precipitation intensity obtained by the CG lightning is closer to the real values from the rain gauge. For example, there was no precipitation in the southeast part of the observation area, as shown in Figs. 6b and $6 \mathrm{c}$, obtained from the CG lightning and the rain gauges, respectively. However, a spurious precipitation area can be identified in Fig. 6a, arising from weak radar echo.

\section{Conclusion}

By analyzing the data of the CG lightning, radar, sounding and other weather indicators at Pingliang, which is located in the eastern Gansu province, from June to August 1997, we have compared the data from several convective weather systems. We find that the CG lightning flash frequency is an important index of the development of the thunderclouds. The correlation coefficient between the CG lightning and the 
precipitation in convective systems is high, and the CG lightning can be used to estimate the convective precipitation. A regression equation between the average precipitation intensity $(R)$ and the number of CG lightning flashes $(L)$ in the main precipitation period is $R=1.69 \ln (L)-0.27$ with a good correlation coefficient $r$ of 0.86 . This method of precipitation estimation is very easy to perform. If the spatial distribution of CG lightning flashes and precipitation is considered, the correlation coefficient may be higher.

Another more detailed kind of precipitation estimation method has been developed. In this method, the spatial and temporal distribution of precipitation relative to the CG lightning flash location and occurrence has been taken into consideration.

The precipitation estimation from the CG lightning flashes is a very useful tool, especially in the regions of poor radar coverage. Of course, inaccuracies in the two methods may arise due to insufficient data coverage. Future work will, therefore, be aimed at improving the data coverage and reducing these inaccuracies.

Acknowledgement. This work was supported by Chinese Academy of Sciences (Grant No. KZCX2-201 and Grant No. 210041) and National Natural Science Foundation of China (Grant No. 49975003).

Topical Editor D. Murtagh thanks V. Rakov and P. Laroche for their help in evaluating this paper.

\section{References}

Buechler, D. E., Wright, P. D., and Goodman, S. J.: Lightning/rainfall relationships during COHMEX. Preprints, 16th Conf. on Severe Local Storms. Kananaski Park, AB Canada, Amer. Meteor. Soc., 710-714, 1990.

Carte, A. E. and Kidder, R. E.: Lightning in relation to precipitation, J. Atmos. Terr. Phys., 39, 139-148, 1977.

Dye, J. E.: Early electrification and precipitation development in a small, isolated Montana cumulonimbus, J. Geophys. Res., 91, 1231-1247, 1986.

Ge, Z. M., Guo, C. M., Yan, M. H., and Meng, Q.: Some characteristics of CG lightning in severe weather. Plateau Meteorology, 14, 1, 40-46, 1995.

Holle, R. L. and Bennett, S. P.: Lightning ground flashes associated with summer 1990 flash floods and streamflow in Tucson, Arizona, an exploratory study, Monthly Weather Review, 125, 1526-1536, 1997.

Krider, E. P., Noggle, R. C., and Uman, M. A.: A gated, wideband magnetic direction for lightning return strokes, J. Appl. Meteor., 15, 301-306, 1976.

Lopez, R. E., Ortiz, R., Otto, W. D., and Holle, R. L.: The lightning activity and precipitation yield of convective cloud systems in central Florida, Preprints, 25th Conf. on Radar Meteorology, Paris, France, Amer. Meteor. Soc., 907-910, 1991.

Peterson, A. W. and Rutledge, S. A.: On the relationship between cloud-to-ground lightning in mesoscale convective rainfall, J. Geophys. Res., 103, D12, 14, 041-057, 1998.

Piepgrass, M. V., Krider, E. P., and Moore, C. B.: Lightning and surface rainfall during Florida thunderstorms, J. Geophys. Res., 89, 11 789-11 805, 1982

Qie, X. S., Yan, M. H., Ge, C. M., and Zhang, G.S.: Lightning data and study of thunderstorm nowcasting, Acta Meteor. Sinica, 7, 2 224-256, 1993.

Sheridan, S., Griffiths, J. H., and Orville, R. E.: Warm season cloud-to-ground lightning-precipitation relationship in the South-Central United States, Weather Forecasting, 11, 417-442, 1996.

Soula, S., Sauvageot, H., Molinie, G., Mesnard, F., and Chauzy, S.: The CG lightning of a storm causing a flash-flood, Geophy. Res. Lett., 25, 8, 1181-1184, 1998.

Tapia, A., Smith, J. A., and Dixon, M.: Estimation of convective rainfall from lightning observations, J. Appl. Meteorol., 37, 1497-1509, 1998.

Watson, A. I. and Holle, R. L.: The relationship between cloud-toground lightning and WSR-88D VIL and cloud-top information. Preprints, Symp. on Global Electrical Circuit, Global Change and the Meteorological Application of Lightning, Nashville, TN, Amer. Meteor. Soc., 325-331, 1994.

Weisman, M. L. and Klemp, J. B.: Characteristics of isolated convective storms. Mesoscale Meteorology and Forecasting, (Ed) Ray, P. S., Amer. Meteor. Soc., 504-520, Weather Forecasting, 10, 592-605, 1986.

Williams, E. R., Weber, M. E., and Orville, R. E.: The relationship between lightning type and convective state of thunderclouds, J. Geophys. Res., 94, 13, 213-220, 1989.

Hongfa, Z. and Baoxiang, X.: Study on rainfall measurement and raindrop spectra with differential reflectivity ZDR technique of dual linear polarization radar, ACTA Meteor. Sinica, 54, 2, 154 165,1996

Zhang, H. F. and Xu, B. X.: Study on rainfall measurement and raindrop spectra with differential reflectivity $\boldsymbol{Z}_{\mathrm{DR}}$ technique of dual linear polarization radar, ACTA Meterological Sinica, 54, 2, 154-165, 1996.

Zhou, Y. J., Zhang, Y. J., Quie, X. S., and Wang, H. B.: The relationship between the variation of hail cloud system and its cloud to ground lightning in the east part of Gansu province, Plateau Meteorology, 18, 2, 236-244, 1999. 